\title{
Evaluation of Pharmacist Intervention on Discharge Medication Reconciliation
}

\author{
Robin Lee, Suzanne Malfair, Jordan Schneider, Sukjinder Sidhu, Caitlin Lang, Nina Bredenkamp, \\ Shu Fei (Sophie) Liang, Alice Hou, and Adil Virani
}

\begin{abstract}
Background: Discharge medication reconciliation (Discharge MedRec) was implemented on one unit at a large urban teaching hospital, and was to be expanded across the rest of the hospital and the health authority's various sites by the end of 2018. Clinical pharmacists on the Acute Care for the Elderly unit carried out discharge planning and led Discharge MedRec during a pilot period, to inform the future implementation.
\end{abstract}

Objectives: The primary objective was to examine the number and type of medication discrepancies before and after implementation of Discharge MedRec. The secondary objectives were to compare documented medication changes, pharmacist recommendations, discharge counselling, communication with community pharmacists, polypharmacy, and 30-day readmission rates.

Methods: Patients seen in December 2015 constituted the control (pre-implementation) group, who received usual care. Patients seen from January to April 2016 constituted the intervention group, for whom pharmacists performed Discharge MedRec and other discharge activities as per the hospital-to-home checklist of the Institute for Safe Medication Practices Canada.

Results: There were 66 patients in the control group and 306 in the intervention group. Median discrepancies per patient decreased from 6.5 to 3 ( $p=0.007$ ), median number of documented changes without rationale increased from 2 to $3(p=0.01)$, and median number of documented changes with rationale increased from 1 to $2(p<0.001)$. Pharmacists made a per-patient median of 1 progress note recommendation in the control group and 2 progress note recommendations in the intervention group $(p=0.007)$, and a per-patient median of 2 orders in both the control and intervention groups $(p=0.62)$. Median recommendation acceptance was $100 \%$ for both groups, but twice as many recommendations were made per patient for the intervention group. Discharge counselling increased from $22.7 \%$ to $65 \%$. Communication with community pharmacists increased from $10.6 \%$ to $60.8 \%$.

Conclusions: Clinical pharmacist involvement improved Discharge MedRec planning and documentation. Decreases in medication discrepancies, combined with an increase in discharge counselling, should improve continuity of care across the health care team and increase patient adherence with medication therapy. This study further demonstrates the leadership role that pharmacists play in the assessment and clear documentation of medication changes at all transitions of care.

Keywords: discharge medication reconciliation, clinical pharmacist, polypharmacy, elderly

\section{RÉSUMÉ}

Contexte : Le processus de bilan comparatif des médicaments au moment du congé a été mis en place dans une unité d'un important hôpital universitaire en milieu urbain et devait être mis en place dans le reste de l'hôpital et dans les différents sites de la régie de santé avant la fin de 2018. Des pharmaciens cliniciens de l'Unité de soins gériatriques de courte durée ont réalisé la planification des congés et ont dirigé le processus de bilan comparatif des médicaments au moment du congé, au cours d'une période d'essai, afin de contribuer à une future mise en place d'un tel processus.

Objectifs : L'objectif principal consistait en l'étude du nombre et du type de divergences relatives aux médicaments avant et après la mise en place du processus de bilan comparatif des médicaments au moment du congé. Les objectifs secondaires portaient sur la comparaison des éléments suivants : les changements apportés à la pharmacothérapie, les recommandations des pharmaciens, l'offre de conseils au moment du congé, les échanges avec les pharmaciens communautaires, la polypharmacie et les taux de réadmissions dans les 30 jours suivant le congé.

Méthodes : Les patients rencontrés en décembre 2015 constituaient le groupe témoin (avant la mise en place du processus) ayant reçu les soins habituels. Les patients rencontrés entre janvier et avril 2016 formaient le groupe expérimental pour lequel les pharmaciens avaient réalisé un processus de bilan comparatif des médicaments au moment du congé et d'autres activités en lien avec le congé, en fonction de la liste de vérification du transfert de l'hôpital à la maison de l'Institut pour la sécurité des médicaments aux patients du Canada.

Résultats : Il y avait 66 patients dans le groupe témoin et 306 dans le groupe expérimental. Le nombre médian de divergences par patient a diminué et est passé de 6,5 à $3(p=0,007)$, le nombre médian de changements consignés, apportés sans raison apparente a augmenté et est passé de 2 à $3(p=0,01)$ et le nombre médian de changements consignés, dont la raison apparaissait aux dossiers a augmenté et est passé de 1 à 2 $(p<0,001)$. Le nombre médian de recommandations par patient dans les notes d'évolution réalisées par les pharmaciens était de un dans le groupe témoin et de deux dans le groupe expérimental $(p=0,007)$ et le nombre médian d'ordonnances par patient réalisées par des pharmaciens était de deux, tant dans le groupe témoin que dans le groupe expérimental $(p=0,62)$. Les taux médians d'acceptation des recommandations étaient de $100 \%$ dans les deux groupes, mais il y a eu deux fois plus de recommandations par patient réalisées dans le groupe expérimental. L'offre de conseils au moment du congé a augmenté et est passée de 22,7 \% à $65 \%$. Les échanges avec les pharmaciens communautaires ont augmenté et sont passés de $10,6 \%$ à $60,8 \%$. 


\section{Can J Hosp Pharm. 2019;72(2):111-8}

Conclusions : La participation des pharmaciens cliniciens a amélioré la planification et l'enregistrement du bilan comparatif des médicaments au moment du congé. Une réduction des divergences concernant les médicaments, associée à une augmentation de l'offre de conseils au moment du congé, devrait améliorer la continuité des soins au sein de l'équipe de soins de santé et accroître l'observance thérapeutique du patient. La présente étude est un nouvel exemple du rôle de leader que les pharmaciens jouent dans l'évaluation et la description claire des changements apportés à la pharmacothérapie à chaque transfert des soins.

Mots clés : bilan comparatif des médicaments au moment du congé, pharmacien clinicien, polypharmacie, aînés

\section{INTRODUCTION}

$\mathrm{M}$ edication reconciliation (MedRec) is described as the "systematic and comprehensive review of all the medications a patient is taking (known as a BPMH [best possible medication history]) to ensure that medications being added, changed or discontinued are carefully evaluated."1 Rozich and Resar ${ }^{2}$ estimated that $60 \%$ of all medication errors occur at admission, at interfaces of transfer, or at discharge. When a patient is transferred from one care setting to another, medications may be stopped or started, or long-term medications may be changed. Unintentional changes at these interfaces lead to discrepancies, which may in turn lead to adverse drug reactions.

Older patients are particularly at risk of such discrepancies, because they are more likely to be receiving multiple concurrent medications (polypharmacy) and to visit a multitude of health care providers. ${ }^{3}$ Evidence has suggested that most adverse drug events leading to readmission among elderly patients occurred within 14 days after discharge, and $8.4 \%$ of such readmissions were due to preventable adverse drug events. ${ }^{4,5}$ Prescribers may be reluctant to change or modify drugs initiated by other prescribers, which leads to the risk of a prescribing cascade (whereby new drugs are prescribed to treat the side effects of previously prescribed drugs).

Clinical pharmacists' recommendations during the patient stay and at discharge could have substantial benefits for patient care. Proactive involvement of a pharmacist during the hospital stay and at discharge has led to recommendations to change doses or to adapt or stop medications. ${ }^{3,6-9}$

Discharge medication reconciliation (Discharge MedRec) is the final checkpoint in the reconciliation process before a patient leaves the hospital. Conflicting information and errors on discharge documents are often problematic, especially for elderly patients and their caregivers. The Institute for Safe Medication Practices Canada found that $67 \%$ of discharge prescriptions were incomplete or contained errors. ${ }^{5}$ The benefits of Discharge MedRec have been cited as increased potential to discover discrepancies, ${ }^{3,10}$ increased opportunities to prevent prescribing cascades, ${ }^{9}$ cost savings as a result of pharmacist interventions, ${ }^{11,12}$ and potentially decreased readmission rates. ${ }^{11,13}$

An accurate medication history is foundational for MedRec and increases patient safety at transitions of care (or at discharge). ${ }^{14}$ The involvement of pharmacists in obtaining a patient's medication history and in the discharge process have shown that they are well suited for identifying medication errors. ${ }^{15-21}$ In several previous studies, the involvement of clinical pharmacists during admission and discharge reduced medication-related problems and readmissions. ${ }^{5,22-24}$ In addition, pharmacist involvement in Discharge MedRec has led to significant cost savings. ${ }^{5,8}$

Across our health authority, Discharge MedRec data focusing on high-risk patients, such as the geriatric population, have not been extensively studied. In a Canadian study performed on an internal medicine unit in 2006, pharmacist involvement revealed unintentional discrepancies that might have been missed on discharge. ${ }^{9}$ Global studies have also demonstrated the benefits of pharmacist involvement in Discharge MedRec, indicating improvements in documentation, increased quality and efficiency of MedRec practices, and increased detection of drug-related problems. ${ }^{3,6,7,12,21}$ These benefits could be attributed in part to pharmacists' special training in managing medications and their potential side effects. It is important to emphasize pharmacy involvement in Discharge MedRec and to continue to advocate for pharmacist involvement at all interfaces of care.

This single-centre, consecutive-cohort study piloted the Discharge MedRec model on the Acute Care for the Elderly (ACE) unit at a large urban teaching hospital, with the aim of measuring the effectiveness of additional pharmacist support at discharge.

\section{METHODS}

\section{Study Design}

This quality assurance initiative was conducted on a single ACE unit. The control group consisted of patients discharged 
from the ACE unit between December 1 and December 31, 2015. The intervention group consisted of patients discharged between January 1 and April 30, 2016. Patients who left against medical advice, who were discharged before pharmacist work-up, or who died in hospital were excluded. The analysis therefore included patients who were undergoing care during the study timeframe and who received pharmacist work-up. The intervention was routine involvement of a clinical pharmacist to assist with Discharge MedRec according to all aspects of the hospital-tohome checklist of the Institute for Safe Medical Practices Canada. ${ }^{5}$ During the intervention phase, an additional pharmacist was staffed to the ward on weekdays to aid with the increased workload associated with this comprehensive care; as such, the patient-to-pharmacist ratio decreased from 36:1 to 18:1 during the intervention phase. Pharmacists were instructed to document, in the patient chart and/or the pharmacy's patient monitoring form, all recommendations, recommendations accepted, cases of patient counselling, and cases of communication with community pharmacists. Both types of documentation were reviewed by a single reviewer (R.L.).

Data collected for analysis included the following:

- total medication changes at discharge

- medication changes documented with and without rationale

- medication changes not documented

- total number of pharmacist recommendations documented through chart notes and orders, subdivided as to type of recommendation (medication started, changed, stopped, other)

- total number of drugs

- total number of patients with medication tapering

- presence or absence of discharge counselling

- communication with community pharmacists

\section{Pre-intervention (Control) Group}

Patients in the control group underwent standard admission and discharge practices in accordance with existing hospital policy. At discharge, the discharge prescription was generated from the list of active medications, and the physician manually filled in preadmission medications that were to be restarted. Pharmacists were consulted as needed during the discharge process, and they contacted the province-wide public drug plan to obtain special authority as needed. The discharge prescription was given to the patient upon discharge.

\section{Intervention Group}

Patients in the intervention group underwent the same admission process as patients in the control group and received the same level of care during their stay in hospital. Pharmacists involved in the study were responsible for medication-related care during each patient's entire stay on the unit. During Discharge MedRec in the intervention phase, the pharmacist reviewed all medications with the physician, ensuring that preadmission and current medications were restarted or continued as necessary. Indications, reversal of auto-substitutions, dose changes, and additions or discontinuations of medications were noted on the Discharge MedRec form. Counselling of patients and communication with community pharmacists were provided at discharge as appropriate. Copies of the resulting Discharge MedRec form were kept in the patient's chart, sent by fax to the patient's community pharmacist, and given to the patient.

\section{Outcomes}

The primary outcome was changes in the number and type of discrepancies (undocumented changes without rationale). The secondary outcomes were changes in the number and type of documented changes (with or without rationale), rate of pharmacist involvement in making recommendations, provision of patient counselling, communication with community pharmacists, and rate of polypharmacy. Thirty-day readmission rates were also examined.

\section{Data Collection}

Pharmacist involvement during the hospital stay and at discharge was evaluated to determine the effect of pharmacist-led Discharge MedRec and to measure pharmacist impact in terms of various medication-related variables (Table 1). Recommendations and discrepancies were categorized in terms of medications started, stopped, or changed (Table 1), with comparisons between the control and intervention groups. Data for recommendations were collected by examining the patient chart and the patient monitoring form. Recommendation acceptance was identified either by documentation (in orders, the patient chart, or the patient monitoring form) of the prescriber's acknowledgement of a pharmacist's recommendation, or by a prescriber's verbal order as transcribed by a pharmacist. Data for discrepancies and medication changes were collected by comparing the Admission MedRec and Discharge MedRec forms.

Data for patient counselling and communication with community pharmacists were collected from indications of such activity either on the Discharge MedRec form, the patient chart, or the patient monitoring form. Data on polypharmacy were collected by tabulating medications listed on the Admission MedRec form and comparing these medications with the Discharge MedRec form. Data regarding tapering of medications were found by examining the patient chart and the Discharge MedRec form. Readmission data were collected at least 1 month after discharge by reviewing the patient's electronic health record for any readmissions throughout the health authority within 30 days of the discharge date. 


\section{Table 1. Definitions}

Type of Change*

Definition

Documented change with rationale Medication changes that were $\quad$ NEw gliclazide SR 30-mg tab PO daily documented and included clear rationale for diabetes

Documented change without rationale $\begin{aligned} & \text { Medication changes that were } \\ & \text { documented, but did not include }\end{aligned} \quad$ NEw calcium carbonate 1250 mg PO daily a rationale

Undocumented change without rationale Medication changes from the Admission 1. acetaminophen $1 \mathrm{~g}$ PO TID MedRec form that were not addressed (not present on Admission MedRec form on the Discharge MedRec form or changes but present on Discharge MedRec form, that appeared on the Discharge MedRec form without explanation with no indication of "NEW"

2. ASA $81 \mathrm{mg}$ PO daily (on Admission MedRec form, but not addressed on Discharge MedRec form)

Total number of changes (documented Sum of all changes listed above

+ undocumented)

Based on the examples above, the total number of changes is 4

MedRec = medication reconciliation .

*Changes made to any of the progress notes, orders, or the Discharge MedRec form were included. If the recommendation or order was present in multiple places, the note of higher quality (i.e., more complete) was used in the evaluation.

tThis column shows information as it appears on the MedRec form, which is available to both the patient and to health care providers. Any entry for a medication that is newly prescribed is to be highlighted, most especially for the patient's benefit.

\section{Statistical Analysis}

All data were coded into a password-protected spreadsheet (Excel 2016 for Windows, Microsoft Corporation). The responses were manually reviewed by one of the investigators (R.L.) in the spreadsheet and verified with the primary investigator (S.M.) before the analyses were performed. All statistical analyses were performed with statistical software (JMP version 12, SAS Institute). Descriptive statistics (medians, totals) were calculated to compare pharmacist notes, types of pharmacist recommendations, involvement in discharge counselling, changes in polypharmacy, and changes in readmission rates. The Fisher exact test was used to analyze differences in baseline characteristics. Mann-Whitney $U$ tests were used to analyze differences in baseline age, medication changes (documented, undocumented, and discrepancies), number of recommendations made and accepted, tapering of medications, and number of active medications on the Admission and Discharge MedRec forms. The $\chi^{2}$ test was used to analyze differences in rates of discharge counselling, communication with community pharmacists, and readmission.

\section{RESULTS}

In total, 72 patients were discharged from the ACE unit in December 2015, of whom 66 met the criteria for inclusion in the control group (i.e., discharged during study timeframe and received pharmacist work-up; Figure 1). In addition, 317 patients were discharged from the ACE unit between January and April 2016, of whom 306 met the inclusion criteria. The small number of patients who left against medical advice or died in hospital were excluded from the analysis. None of the patients who received pharmacist work-up left against medical advice. The median age of patients in the control and intervention groups was 83 and 83.5 years respectively (Table 2). The control group had $28.8 \%$ men $(19 / 66)$, and the intervention group had $47.1 \%$ men
(144/306). The median length of stay was 18.5 days in the control group and 9.5 days in the intervention group $(p<0.001)$.

When medication changes were analyzed (Table 3 ), the median number of discrepancies (undocumented changes without rationale) was 6.5 in the control group and 3 in the intervention group $(p=0.007)$. The median number of documented changes without rationale was 2 in the control group and 3 in the intervention group $(p=0.01)$, and the median number of documented changes with rationale was 1 in the control group and 2 in the intervention group $(p<0.001)$. The median number of pharmacist recommendations doubled between the control and intervention phases of the study (Table 3). The median acceptance rate for recommendations was $100 \%$ in both groups $(p<0.001)$, with twice the number of recommendations per patient in the intervention group. The median number of pharmacist orders was the same in the 2 groups.

Polypharmacy data are also shown in Table 3 . The rate of tapering was $4.5 \%(3 / 66)$ in the control group and $6.9 \%$ $(21 / 306)$ in the intervention group $(p=0.75)$. Patients in the control group had a median of 8.5 active medications upon admission and a median of 9 medications at discharge, whereas patients in the intervention group had a median of 6 medications upon admission and 9 medications upon discharge.

Discharge counselling was provided for 22.7\% (15/66) of patients in the control group and for 65.0\% (199/306) of patients in the intervention group $(p<0.001)$. Communication with community pharmacists increased from $10.6 \%(7 / 66)$ in the control group to $60.8 \%(186 / 306)$ in the intervention group $(p<0.001)$. Thirty-day readmission rates were $28.8 \%(19 / 66)$ in the control group and $21.2 \%(65 / 306)$ in the intervention group $(p=0.17)$.

\section{DISCUSSION}

Previous studies of MedRec have acknowledged the importance of pharmacist involvement at both admission and discharge. In the current study, clinical pharmacist involvement in Discharge 
This single copy is for your personal, non-commercial use only.

For permission to reprint multiple copies or to order presentation-ready copies for distribution, contact CJHP at publications@cshp.ca

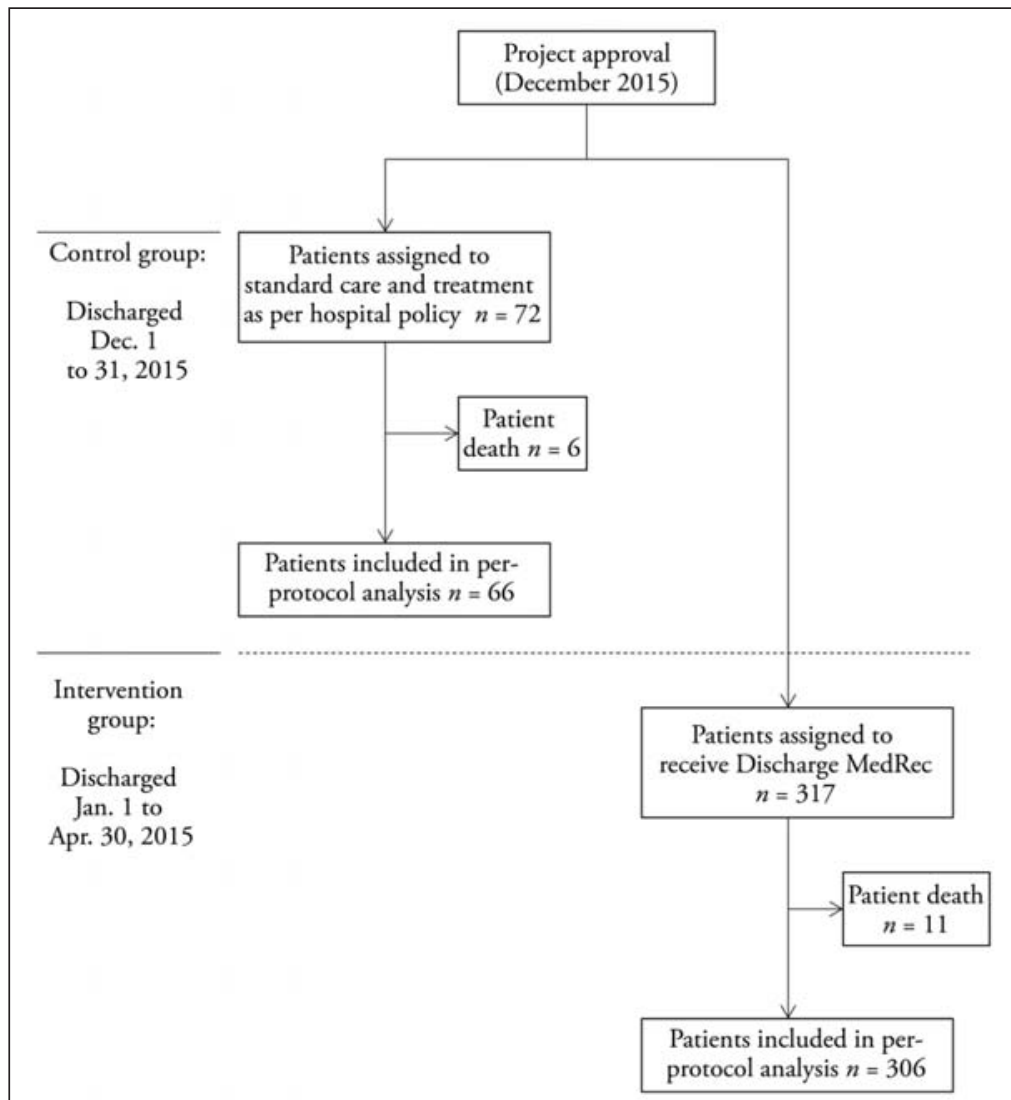

Figure 1. Timeline of study.

\section{Table 2. Baseline Characteristics of Study Groups}

\begin{tabular}{|c|c|c|c|c|c|}
\hline \multirow{3}{*}{$\begin{array}{l}\text { Characteristic } \\
\text { Age (years) (median, IQR) }\end{array}$} & \multicolumn{4}{|c|}{ No. (\%) of Patients* } & \multirow[b]{2}{*}{$p$ Value } \\
\hline & \multicolumn{2}{|c|}{ Control $(n=66)$} & \multicolumn{2}{|c|}{ Intervention $(n=306)$} & \\
\hline & 83 & $(77-89)$ & 83.5 & $(78-89)$ & $0.13 \neq$ \\
\hline$\overline{\text { Sex }}$ & & & & & $0.16 \S$ \\
\hline Men & 19 & $(28.8)$ & 144 & $(47.1)$ & \\
\hline Women & 47 & $(71.2)$ & 162 & $(52.9)$ & \\
\hline \multicolumn{6}{|l|}{ Admission diagnosest } \\
\hline Infectious disease & 25 & (37.9) & 108 & (35.3) & $0.78 \uparrow$ \\
\hline Cardiovascular condition & 15 & $(22.7)$ & 62 & (20.3) & 0.629 \\
\hline Failure to thrive/weakness & 5 & (7.6) & 50 & (16.3) & 0.089 \\
\hline Respiratory condition & 8 & $(12.1)$ & 36 & (11.8) & $>0.999$ \\
\hline Fluid/electrolyte problem & 1 & $(1.5)$ & 20 & $(6.5)$ & 0.149 \\
\hline Blood/renal condition & 2 & (3.0) & 17 & $(5.6)$ & 0.559 \\
\hline Gastrointestinal/genitourinary condition & 3 & (4.5) & 12 & (3.9) & $0.74 \uparrow$ \\
\hline Neurologic condition & 6 & (9.1) & 11 & (3.6) & $0.09 \emptyset$ \\
\hline Endocrine condition & 2 & (3.0) & 3 & (1.0) & 0.229 \\
\hline Liver/pancreas problem & 2 & (3.0) & 1 & $(0.3)$ & 0.089 \\
\hline Other & 10 & $(15.2)$ & 74 & $(24.2)$ & $0.14 \uparrow$ \\
\hline
\end{tabular}

$\mathrm{QQR}=$ interquartile range

*Except where indicated otherwise.

†Medical conditions that encompassed $\geq 2 \%$ of the patient population on the Acute Care for the Elderly unit are listed; some patients had more than one condition.

$\neq$ Calculated with Mann-Whitney $U$ test.

$\S$ Calculated with $\chi^{2}$ test.

ICalculated with the Fisher exact test. 
Table 3. Outcomes

\begin{tabular}{|c|c|c|c|c|c|}
\hline \multirow{3}{*}{$\begin{array}{l}\text { Outcome } \\
\text { No. of discrepancies }\end{array}$} & \multicolumn{4}{|c|}{ Median Value (IQR)* } & \multirow[b]{2}{*}{$p$ Value } \\
\hline & \multicolumn{2}{|c|}{$\begin{array}{l}\text { Control } \\
(n=66)\end{array}$} & \multicolumn{2}{|c|}{$\begin{array}{l}\text { Intervention } \\
(n=306)\end{array}$} & \\
\hline & & & & & \\
\hline Undocumented changes without rationale & 6.5 & $(1-11)$ & 3 & $(1-6)$ & $0.007 \dagger$ \\
\hline Total "medications started" & 6.5 & $(1-11)$ & 3 & $(1-6)$ & $0.006 \dagger$ \\
\hline Total "medications changed" & 0 & $(0)$ & 0 & $(0)$ & Not tested \\
\hline Total "medications stopped" & 0 & (0) & 0 & (0) & Not tested \\
\hline Documented changes without rationale & 2 & $(1-3)$ & 3 & $(1-6)$ & $0.01 \dagger$ \\
\hline Documented changes with rationale & 1 & $(0-2)$ & 2 & $(1-4)$ & $<0.001 \dagger$ \\
\hline Total changes (documented + undocumented) & 10 & $(6-14.75)$ & 10 & $(5.25-14)$ & $0.84 \dagger$ \\
\hline \multicolumn{6}{|l|}{ No. of pharmacist recommendations } \\
\hline Made in progress notes & 1 & $(1-2)$ & 2 & $(1-4)$ & $0.007 \dagger$ \\
\hline Accepted in progress notes & 1 & $(0-2)$ & 2 & $(0-4)$ & $<0.001 \dagger$ \\
\hline Pharmacist orders (in orders and directives) & 2 & $(1-3)$ & 2 & $(0-4)$ & $0.62+$ \\
\hline \multicolumn{6}{|l|}{ Polypharmacy } \\
\hline No. of active medications identified on Admission MedRec form & 8.5( & $(4.25-10.75)$ & 6 & $(3-10)$ & $0.81+$ \\
\hline No. of medications upon discharge & 9 & $(5-13)$ & 9 & $(6-12)$ & Not tested \\
\hline Total no. (\%) of patients with tapering upon discharge & 3 & $(4.5)$ & 21 & $(6.9)$ & $0.75 t$ \\
\hline \multicolumn{6}{|l|}{ Patient outcomes } \\
\hline No. (\%) of patients who received counselling & 15 & $(22.7)$ & 199 & $(65.0)$ & $<0.001 \neq$ \\
\hline $\begin{array}{l}\text { No. (\%) of patients with communication between hospital } \\
\text { pharmacist and patient's community pharmacists }\end{array}$ & 7 & $(10.6)$ & 186 & $(60.8)$ & $<0.001 \neq$ \\
\hline No. $(\%)$ of patients readmitted within 30 days & 19 & $(28.8)$ & 65 & $(21.2)$ & $0.17 \neq$ \\
\hline
\end{tabular}

MedRec improved medication discharge planning and documentation. This study has further demonstrated the leadership role that pharmacists play in the assessment, clarification, and clear documentation of medication changes during a patient's stay and, more importantly, during the discharge process. These findings reinforce calls for additional pharmacist support in maintaining MedRec at care transitions, the use of pharmacists as educators to demonstrate Discharge MedRec best practices, and the continued affirmation of the pharmacist's role as a medication manager. These findings are also consistent with previous research in this area. ${ }^{11,12}$

In this study, the median number of discrepancies decreased by $54 \%$ (from 6.5 to $3 ; p=0.007$ ). Levels of documented changes both with and without rationale increased in the intervention group relative to the control group: by $100 \%(p<0.001)$ and by $50 \%(p<0.01)$, respectively. The median number of changes overall was the same in the 2 groups $(p=0.84)$; however, more documentation and rationale were provided for changes in the intervention group. "Medications started" discrepancies decreased by $54 \%$ in the intervention group (Table 3). "Medication changed" and "medication stopped" discrepancies were so few that the median remained unchanged at zero. This is possibly because changes are usually initiated during the stay rather than at point of discharge, and there is usually some form of documentation for such changes.

Relative to the control group, the median number of pharmacist recommendations per patient doubled in the intervention group, whereas the median number of pharmacist orders per patient was unchanged. The median proportion of pharmacist recommendations accepted was $100 \%$ in both groups, but twice the number of recommendations were made in the intervention group $(p=0.007)$. These trends matched both the Belgian and global studies., 3,7,14,25 Other studies have also suggested that pharmacist recommendations may help in avoiding potential medication discrepancies. ${ }^{7,10}$

Medications were tapered for $4.6 \%$ of patients in the control group and $6.9 \%$ of those in the intervention group ( $p=0.75)$; however, the total number of discharge medications increased in both groups. The overall increase in the number of discharge medications may be explained by several factors. The current Admission MedRec process captures province-wide prescription medications, whereas most over-the-counter medications must be manually added to the patient's record and are sometimes missed. Discharge medication lists are generated from in-hospital databases and include all active over-the-counter medications, which might explain the higher number of medications upon discharge. Over-the-counter medications, such as calcium for bone health, ${ }^{26}$ vitamin $\mathrm{D}$ for reducing falls risk, ${ }^{26,27}$ and acetaminophen for osteoarthritis-related pain, ${ }^{28}$ are often prescribed for geriatric patients. Concerted efforts to increase training regarding documentation of over-the-counter medications and to increase efforts to monitor and discontinue medications are particularly important for optimizing therapy for geriatric patients. 
Relative to the control group, there was an absolute increase of $42 \%$ in provision of discharge counselling to patients in the intervention group $p<0.001)$, and an absolute increase of $50 \%$ in contact with community pharmacies $(p<0.001)$. These actions should improve continuity of care across the health care team, patient satisfaction, and adherence with medication therapy, and ultimately should decrease medication discrepancies. ${ }^{29}$ Pharmacist involvement may be increased by the introduction of a formal Discharge MedRec process.

The median rate of readmission was $28.8 \%$ for the control group and $21.2 \%$ for the intervention group ( $p=0.17$ ); however, this aspect of the analysis was not sufficiently powered to detect a significant difference had it been present. Many factors can affect readmission rates, including medication discrepancies, but also severity of condition, comorbid conditions, race, economic status, age, and previous hospital admissions. ${ }^{30}$ A larger study with multivariate analysis specifically designed to examine readmission rates as a result of Discharge MedRec (i.e., preventing and resolving medication discrepancies) might show a statistically significant difference. Sebaaly and others ${ }^{11}$ suggested that 30 -day readmission rates dropped $2 \%$ as a result of Discharge MedRec, and they predicted that the decrease in readmission rates due to pharmacist interventions would result in significant cost savings.

Further cost savings could be achieved with the inclusion of pharmacy technicians in the MedRec process. The basis for any good MedRec process is a best possible medication history, and there is a clear role for pharmacy technicians in obtaining best possible medication histories. ${ }^{12,31}$ Depending on the jurisdiction, pharmacy technicians may have other roles; however, in our area, the current scope of practice of pharmacy technicians limits their clinical involvement to taking medication histories and clerical functions such as preparation of dosing calendars and sending faxes to community pharmacies.

The major strengths of this study include its large sample size, with a combined total of 372 patients followed during the entire study period. Multiple aspects of pharmacist involvement were examined, and a detailed analysis of pharmacist recommendations and orders was performed. However, the study also had some potential limitations. The control and intervention phases of the study ran consecutively, not simultaneously. Medication discrepancies identified in hospital were not rated in terms of their potential to cause harm. Comprehensive postdischarge follow-up was not conducted. At times, language posed a significant communication barrier between the pharmacist and the patient, although efforts were made to enhance communication, either by using translators or by speaking to a patient's community pharmacy or caregivers. We were unable to analyze characteristics of the minority of patients who left against medical advice or patients who were discharged from the ward before pharmacist work-up. Opportunities for future research include adverse events analysis, determination of patient satisfaction and patients' adherence to medication therapy plans after discharge, and involvement of pharmacy technicians in MedRec.

At the patient level, postdischarge adverse events could be examined in relation to high-risk medication classes and geriatric prescribing guidelines, such as the Beers criteria. Patient satisfaction could be assessed to inform MedRec processes. At the site level, time-and-motion studies and per-patient cost analyses before and after implementation of MedRec could be used to plan and evaluate Discharge MedRec. At the health authority level, multiple sites could attempt the same pilot study to determine practicality.

\section{CONCLUSION}

A pharmacist-led Discharge MedRec service was successful in decreasing discrepancies, providing more documented and accepted recommendations, and improving discharge planning. In light of the positive results of this pilot study and subsequent requests from physicians, additional pharmacist staffing has remained on the ACE unit, and work is under way to expand Discharge MedRec to high-risk patients on other wards.

\section{References}

1. Medication reconciliation (MedRec). Toronto (ON): Institute for Safe Medication Practices Canada; 2016 [cited 2016 Jun 18]. Available from: https://www.ismp-canada.org/medrec/

2. Rozich JD, Resar RK. Medication safety: one organization's approach to the challenge. J Clin Outcomes Manag. 2001;8(10):27-34.

3. Unroe KT, Pfeiffenberger T, Riegelhaupt S, Jastrzembski J, Lokhnygina Y, Colón-Emeric C. Inpatient medication reconciliation at admission and discharge: a retrospective cohort study of age and other risk factors for medication discrepancies. Am J Geriatric Pharmacother. 2010;8(2):115-26.

4. Kanaan AO, Donovan JL, Duchin NP, Field TS, Tjia J, Cutrona SL, et al. Adverse drug events after hospital discharge in older adults: types, severity, and involvement of Beers criteria medications. J Am Geriatr Soc. 2013; 61(11):1894-9.

5. Hospital to home-facilitating medication safety at transitions (a toolkit for healthcare providers). Toronto (ON): Institute for Safe Medication Practices Canada; [cited 2019 Mar 11]. Available from: https://www.ismpcanada.org/transitions/download-toolkit.php

6. Dodds LJ. Pharmacist contributions to ensuring safe and accurate transfer of written medicines-related discharge information: lessons from a collaborative audit and service evaluation involving 45 hospitals in England. Eur J Hosp Pharm Sci Pract. 2014;21(3):150-5.

7. Bourne RS, Choo CL. Pharmacist proactive medication recommendations using electronic documentation in a UK general critical care unit. Int J Clin Pharm. 2012;34(2):351-7.

8. Karapinar-Çarkit F, Borgsteede SD, Zoer J, Egberts TCG, van den Bemt PMLA, van Tulder M. Effect of medication reconciliation on medication costs after hospital discharge in relation to hospital pharmacy labor costs. Ann Pharmacother. 2012;46(3):329-38.

9. Wong JD, Bajcar JM, Wong GG, Alibhai SM, Huh JH, Cesta A, et al. Medication reconciliation at hospital discharge: evaluating discrepancies. Ann Pharmacother. 2008;42(10):1373-9.

10. Bishop MA, Cohen BA, Billings LK, Thomas EV. Reducing errors through discharge medication reconciliation by pharmacy services. Am J Health Syst Pharm. 2015;72(17 Suppl 2):S120-6.

11. Sebaaly J, Parsons LB, Pilch NA, Bullington W, Hayes GL, Easterling H. Clinical and financial impact of pharmacist involvement in discharge medication reconciliation at an academic medical center: a prospective pilot study. Hosp Pharm. 2015;50(6):505-13. 
This single copy is for your personal, non-commercial use only.

For permission to reprint multiple copies or to order presentation-ready copies for distribution, contact CJHP at publications@cshp.ca

12. Najafzadeh M, Schnipper JL, Shrank WH, Kymes S, Brennan TA, Choudhry NK. Economic value of pharmacist-led medication reconciliation for reducing medication errors after hospital discharge. Am J Manag Care. 2016;22(10):654-61.

13. Zemaitis CT, Morris G, Cabie M, Abdelghany O, Lee L. Reducing readmission at an academic medical center: results of a pharmacy-facilitated discharge counseling and medication reconciliation program. Hosp Pharm. 2016; 51(6):468-73.

14. Sproul A, Goodine C, Moore D, McLeod A, Gordon J, Digby J, et al. Quality of best possible medication history upon admission to hospital: comparison of nurses and pharmacy students and consideration of national quality indicators . Can J Hosp Pharm. 2018;71(2):128-34.

15. Tam VC, Knowles SR, Cornish PL, Fine N, Marchesano R, Etchells EE. Frequency, type and clinical importance of medication history errors at admission to hospital: a systematic review. CMAJ. 2005;173(5):510-5.

16. Reeder TA, Mutnick A. Pharmacist- versus physician-obtained medication histories. Am J Health Syst Pharm. 2008;65(9):857-60.

17. Carter MK, Allin DM, Scott LA, Grauer D. Pharmacist-acquired medication histories in a university hospital emergency department. Am J Health Syst Pharm. 2006;63(24):2500-3.

18. Caroff DA, Bittermann T, Leonard CE, Gibson GA, Myers JS. A medical resident-pharmacist collaboration improves the rate of medication reconciliation verification at discharge. Jt Comm J Qual Patient Saf. 2015; 41(10):457-61.

19. Abdel-Qader DH, Harper L, Cantrill JA, Tully MP. Pharmacists' interventions in prescribing errors at hospital discharge: an observational study in the context of an electronic prescribing system in a UK teaching hospital. Drug Saf. 2010;33(11):1027-44.

20. Feldman LS, Costa LL, Feroli ER Jr, Nelson T, Poe SS, Frick KD, et al. Nurse-pharmacist collaboration on medication reconciliation prevents potential harm. J Hosp Med. 2012;7(5):396-401.

21. Allende Bandrés MÁ, Arenere Mendoza M, Gutiérrez Nicolás F, Calleja Hernández MÁ, Ruiz La Iglesia F. Pharmacist-led medication reconciliation to reduce discrepancies in transitions of care in Spain. Int J Clin Pharm. 2013;35(6):1083-90.

22. Warden BA, Freels JP, Furuno JP, Mackay J. Pharmacy-managed program for providing education and discharge instructions for patients with heart failure. Am J Health Syst Pharm. 2014;71(2):134-9.

23. Koehler BE, Richter KM, Youngblood L, Cohen BA, Prengler ID, Cheng $\mathrm{D}$, et al. Reduction of 30-day postdischarge hospital readmission or emergency department (ED) visit rates in high-risk elderly medical patients through delivery of a targeted care bundle. J Hosp Med. 2009;4(4):211-8.

24. Gillespie U, Alassaad A, Henrohn D, Garmo H, Hammarlund-Udenaes M, Toss $\mathrm{H}$, et al. A comprehensive pharmacist intervention to reduce morbidity in patients 80 years or older: a randomized controlled trial. Arch Intern Med. 2009;169(9):894-900.

25. Keeys C, Kalejaiye B, Skinner M, Eimen M, Neufer J, Sidbury G, et al. Pharmacist-managed inpatient discharge medication reconciliation: a combined onsite and telepharmacy model. Am J Health Syst Pharm. 2014; 71(24):2159-66.

26. Annweiler C, Montero-Odasso M, Schott AM, Berrut G, Fantino B, Beauchet O. Fall prevention and vitamin D in the elderly: an overview of the key role of the non-bone effects. J Neuroeng Rehabil. 2010;7:50.

27. Garriguet D. Bone health: osteoporosis, calcium and vitamin D. Health Rep. 2011;22(3):7-14.

28. Flood J. The role of acetaminophen in the treatment of osteoarthritis. Am J Manag Care. 2010;16 Suppl Management:S48-54.

29. Sarangarm P, London MS, Snowden SS, Dilworth TJ, Koselke LR, Sanchez $\mathrm{CO}$, et al. Impact of pharmacist discharge medication therapy counseling and disease state education: pharmacist assisting at routine medical discharge (Project PhARMD). Am J Med Qual. 2013;28(4):292-300.
30. Horney C, Capp R, Boxer R, Burke RE. Factors associated with early readmission among patients discharged to post-acute care facilities. J Am Geriatr Soc. 2017;65(6):1199-205.

31. Bailey JE, Surbhi S, Bell PC, Jones AM, Rashed S, Ugwueke MO. SafeMed: using pharmacy technicians in a novel role as community health workers to improve transitions of care. J Am Pharm Assoc. 2016;56(1):73-81.

Robin Lee, BScPharm, BSc, is a Pharmacist with the Surrey Memoria Hospital and the Jim Pattison Outpatient Care and Surgery Centre, Surrey, British Columbia.

Suzanne Malfair, BSC(Pharm), ACPR, PharmD, FCSHP, BCPS, is Coordinator, Clinical Pharmacy Services, with Lions Gate Hospital and The University of British Columbia, North Vancouver, British Columbia.

Jordan Schneider, PharmD, MS, BCPS, is a Clinical Pharmacist with the Jim Pattison Outpatient Care and Surgery Centre, Surrey Memorial Hospital, Surrey, British Columbia.

Sukjinder Sidhu, BSc(Pharm), ACPR, is a Clinical Pharmacist with Surrey Memorial Hospital, Surrey, British Columbia.

Caitlin Lang, BSc(Pharm), ACPR, is a Clinical Pharmacist with Surrey Memorial Hospital, Surrey, British Columbia.

Nina Bredenkamp, BSc(Pharm), ACPR, is a Clinical Pharmacist with Surrey Memorial Hospital, Surrey, British Columbia.

Shu Fei (Sophie) Liang, BSC(Pharm), is a Pharmacist with Surrey Memorial Hospital, Surrey, British Columbia.

Alice Hou, BSc(Pharm), ACPR, is a Clinical Pharmacist with Surrey Memorial Hospital, Surrey, British Columbia.

Adil Virani, BSc(Pharm), PharmD, is the Manager of Pharmacy Services, Lower Mainland Pharmacy Services, and Associate Professor, Faculty of Pharmaceutical Sciences, The University of British Columbia, Vancouver, British Columbia.

Competing interests: None declared.

\section{Address correspondence to:}

\section{Dr Suzanne Malfair}

Lions Gate Hospital

The University of British Columbia

231 15th Street $\mathrm{E}$

North Vancouver BC V7L 2L7

e-mail: Suzanne.malfair@vch.ca

Funding: None received.

Acknowledgement: The authors would like to acknowledge Alison Alleyne, Clinical Manager with Lower Mainland Pharmacy Services, Fraser Health, for her contributions to the design and resourcing of the project; Patrick Ching, Pharmacist with Surrey Memorial Hospital, Fraser Health, for his contribution to the collection of project data; Tina Murphy, Ambulatory Care Coordinator with Community Outpatient Services, Fraser Health, for coordination of the ACE unit interdisciplinary team; Jennifer Caryk, Nurse with Educational Activities, Fraser Health, for her contribution to MedRec education; and Anureet Sohi, Pharmacist with Fraser Health, for her contribution to the study design. 